\title{
SEQUENCE OF STRUCTURAL CHANGES IN CULTURES OF CLOSTRIDIUM TETANI GROWN ON A SOLID MEDIUM
}

\author{
Judith F. M. HoENIGER AND H.-D. TAUSCHEL* \\ Department of Microbiology, University of Toronto, Toronto, Canada
}

\section{Plates XX-XXV}

THE majority of Clostridium tetani strains will gradually completely spread as a very delicate film across the surface of a solid medium such as blood agar. This phenomenon of swarming growth is of diagnostic importance (Willis, 1964; Willis and Williams, 1970) and can also be made use of in the isolation of C. tetani from a mixture with other bacteria (Fildes, 1925). Swarming is demonstrated by other clostridia, for example $C$. novyi (Turner and Eales, 1941) and C. septicum (Willis, 1964; Willis and Williams, 1972); by some species of Bacillus (Sasarman, Ganea and Dospina, 1957) such as B. alvei (Henrichsen, 1972); and by Proteus vulgaris and P. mirabilis (see Hoeniger, 1964, 1965, 1966, for reviews of the literature).

The present paper describes the sequence of structural changes observed in a strain of $C$. tetani during swarming growth. Cell morphology was studied by phase-contrast microscopy of agar-block preparations and by electron microscopy of negatively-stained preparations of whole organisms. We have also studied the distribution of cellular components such as nuclei and cytoplasm in swarmers stained for ordinary light microscopy or in similar cells embedded and sectioned for electron microscopy. Such a detailed investigation of $C$. tetani has not previously been carried out although the cytology of swarming of this bacterium was briefly discussed by Henrichsen (1972) in a general review of bacterial surface translocation.

\section{MATERIALS AND METHODS}

\section{Organism, culture media and procedures}

The organism used was $C$. tetani NCTC9575. Stock cultures were grown for 3 days in Bacto-Cooked Meat Medium (Difco) at $37^{\circ} \mathrm{C}$, and then held at room temperature for 10 days to induce sporulation (Takagi, Nakamura and Ueda, 1965); glycerol was added to a final concentration of $10 \%$ and $1-2 \mathrm{ml}$ samples of the glycerinated culture were stored at $-10^{\circ} \mathrm{C}$. For use, a glycerinated culture was thawed and inoculated into TPGY broth (described below) and grown overnight at $37^{\circ} \mathrm{C}$. Cells from TPGY broth were spread according to the appropriate method on TPGY agar; for phase-contrast studies $1 \mathrm{ml}$ of this medium was poured into a 10-cm glass Petri dish already containing a sterile glass slide and then dried for $5-10 \mathrm{~min}$. at $37^{\circ} \mathrm{C}$; when cells were to be stained for their nuclei or cytoplasm, $15 \mathrm{ml}$ of the agar in a dish was dried for $20-25 \mathrm{~min}$.

Received 13 Dec. 1973; accepted 7 Feb. 1974.

* Present Address: Lehrstühl für Mikrobiologie, Institüt fur Biologie II, Universität Freiburg, West Germany.

J. MED. MICROBIOL.-VUL. 7 (1974) 
TPGY broth (Eklund, Poysky and Boatman, 1969) contains trypticase, 5\%; peptone, $0.5 \%$; glucose, $0.1 \%$; yeast extract, $0.5 \%$; and sodium thioglycollate, $0.1 \%$; final $p \mathrm{H} 7 \cdot 1$. TPGY agar was prepared with $2.0 \%$ Noble (Difco) agar. For de-areation, liquid media were boiled for $15 \mathrm{~min}$., then cooled. Agar plates were incubated in an anaerobic jar (Baird and Tatlock, London) under hydrogen at $37^{\circ} \mathrm{C}$.

To study changes with phase-contrast microscopy during the first 6 hours of growth, the inoculum was spread with a $5-\mathrm{mm}$ loop in a stroke overlying the slide cast into the agar; for observations after incubation for 24,48 and 72 hours, the inoculum was spread to a width of about $1 \mathrm{~cm}$ at one side of the dish and at right angles to the length of the slide.

\section{Studies with light microscopy}

For observation of "living" cells with the phase-contrast microscope, blocks of agar (approximately $10 \mathrm{~mm}$ square and $1 \mathrm{~mm}$ deep) were excised from above the immersed slide, mounted on a second slide, cell-side upwards, covered carefully with a no. 0 grease-free glass slip, and sealed on two sides with wax from a small candle.

To stain either the nuclei or cytoplasm, blocks of agar were cut at the edge of swarming with an iridectomy knife, and inverted on to grease-free no. 1 cover-glasses to make impression prints. In preparation for nuclear staining by the osmium-HCl-Giemsa method (Robinow, 1942 and 1944), the cover-glasses bore a film of dried $8 \% \mathrm{egg}$ white to prevent coalescence of the cells. Further, the staining time with Giemsa was prolonged to 2 hours at $37^{\circ} \mathrm{C}$ and the preparations were counter-stained for $1 \mathrm{~min}$. in $0.01 \%$ basic fuchsin prepared in phosphate buffer, $p \mathrm{H} \mathrm{6.8}$. The cytoplasm was stained with $0.01 \%$ thionin for $7.5 \mathrm{~min}$., after the bacteria had been fixed in situ through the agar with Bouin's fluid for 1 hour (Robinow, 1944).

Preparations were photographed through a Zeiss Universal microscope equipped with Optovar (set at 1.25), $8 \times$ compensating ocular, an achromatic aplanatic condenser (VZ) of N.A. 1.4 , and either a neofluor phase-contrast $100 \times$ objective with N.A. 1.3 or a planachromatic $100 \times$ objective having N.A. 1-32. Light from a tungsten filament lamp was adjusted to give Koehler illumination. It was passed through a broad-band green interference filter (Schott, $546 \mathrm{~nm}$ ) for phase-contrast examination; and through either a green glass filter (Zeiss VG 9) in combination with an orange gelatin filter (Wratten No. 22) to increase contrast in the nuclei, or through a narrow-band green interference filter (Schott $546 \pm 5 \mathrm{~nm}$ ) for cytoplasm.

\section{Studies with electron microscopy}

For thin sectioning, swarmers were fixed with osmium tetroxide according to the method of Ryter and Kellenberger (R-K; Ryter and Kellenberger, 1958), post-fixed with 0.5\% uranyl acetate, dehydrated in a graded series of alcohols, passed through propylene oxide, followed by propylene oxide plus Epon $812(1: 1)$, and embedded in Epon. Sections were cut on a Porter-Blum ultramicrotome MT-2 with a diamond knife. They were doubly stained with $2.0 \%$ uranyl acetate for $20 \mathrm{~min}$. followed by lead citrate for $10 \mathrm{~min}$.

For negative staining, overnight broth cultures (inoculum) were washed and resuspended in distilled water at $p \mathbf{H ~ 7 . 0}$; cells removed from appropriate regions of plate cultures were likewise taken up in distilled water, $p \mathrm{H} \mathrm{7.0.} \mathrm{One} \mathrm{part} \mathrm{of} \mathrm{the} \mathrm{bacterial} \mathrm{suspension} \mathrm{was} \mathrm{then}$ mixed with one part of a mixture of $2.0 \%$ sodium phosphotungstate (Na-PTA, $p \mathrm{H} \mathrm{7 \cdot 1)}$ and $0.05 \%$ bovine serum albumin (BSA), $p \mathrm{H} \mathrm{7.0} \mathrm{(Hoeniger,} \mathrm{1965).} \mathrm{A} \mathrm{drop} \mathrm{of} \mathrm{the} \mathrm{preparation}$ was placed on a grid covered with a Formvar film reinforced with carbon, and excess fluid removed after $15 \mathrm{~s}$ with a wick of filter paper.

Micrographs were taken with a Philips 300 electron microscope operating at $60 \mathrm{kV}$.

\section{RESULTS}

\section{Observations by phase-contrast microscopy}

The sequence of changes on an agar medium could be followed by excising blocks from plates that had been incubated for varying periods of time, i.e., at 
Structural Changes in Clostridium tetani
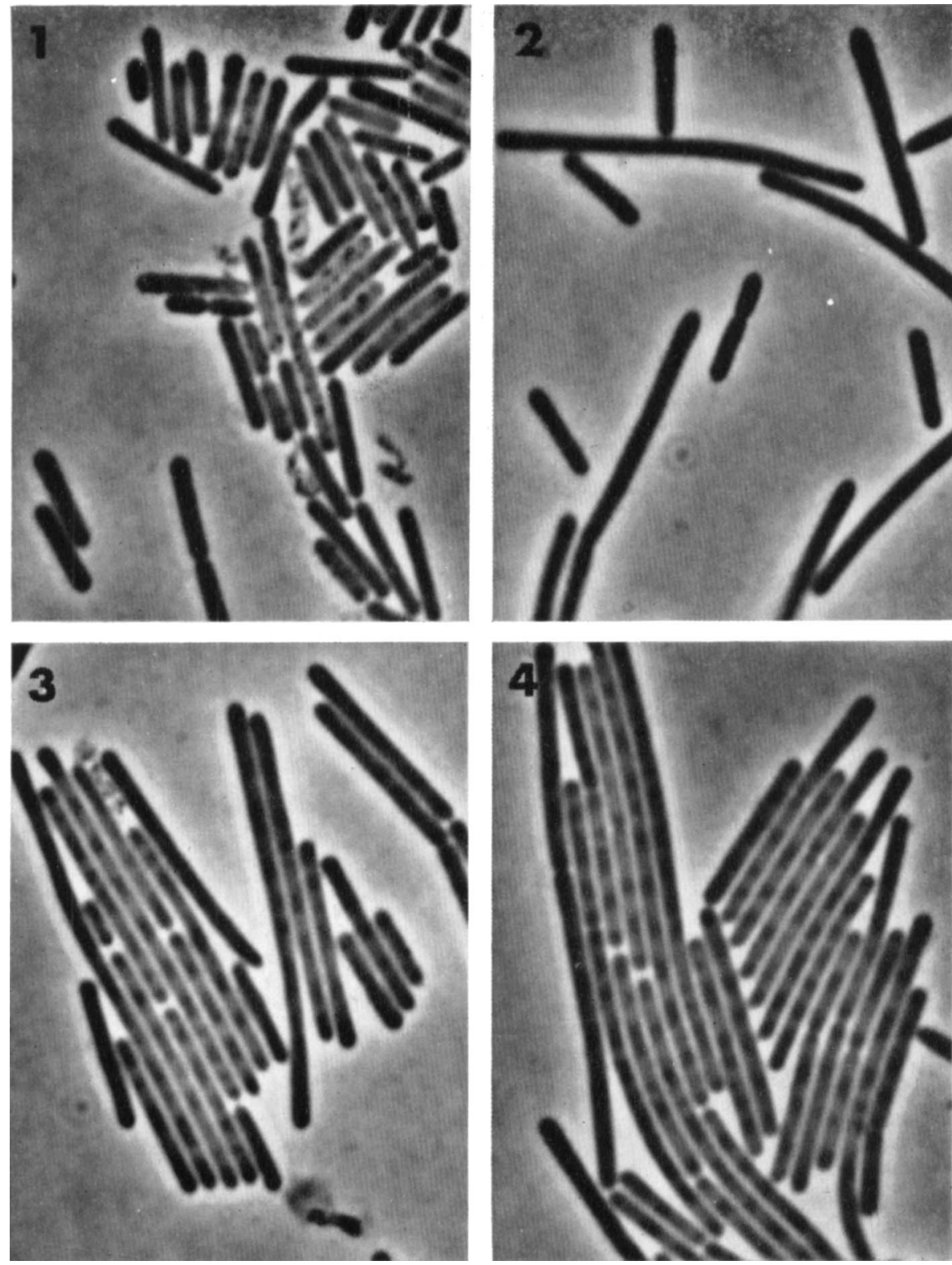

FIGS. 1-4.-Sequence of changes in an agar slide culture of C. tetani excised after incubation for 2 , 3,4 and 6 hours. Phase-contrast microscopy. $\times 2400$. 

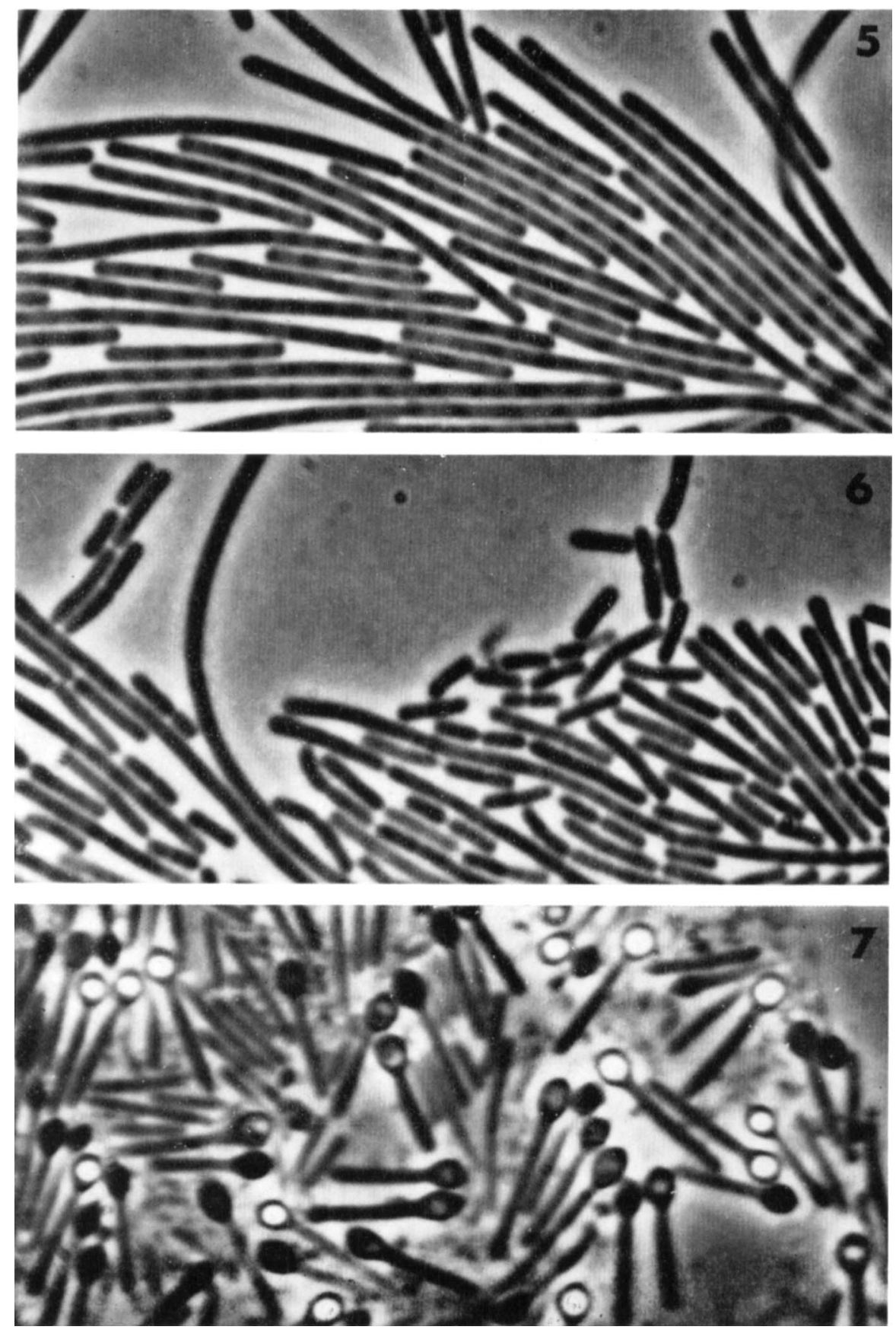

Figs. 5 and 6.-Edge of growth in an agar slide culture after incubation for 24 and 48 hours. Phase-

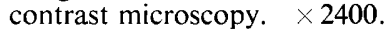

Fig. 7.-Cells bearing forespores or mature spores interspersed with lysing bacteria. Agar slide culture excised from a 72-hour plate. Phase-contrast microscopy. $\times 2400$. 

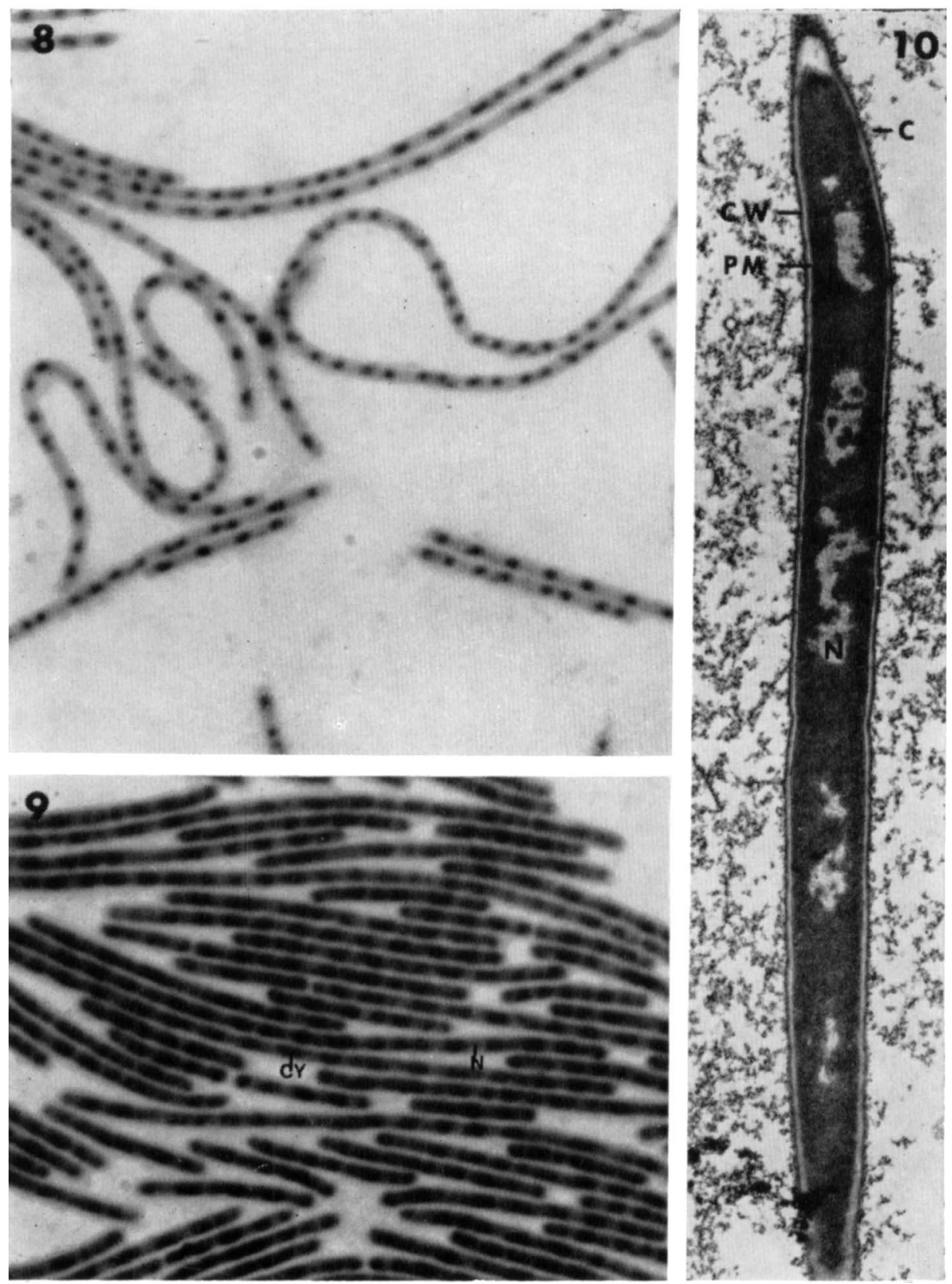

FIG. 8. - Nuclei in swarmers. Osmium-HCl-Giemsa technique. Ordinary light microscopy. $\times 2000$ FIG. 9.--Staining of cytoplasmic bands in swarmers by Bouin-thionin procedure. CY, cytoplasm; $\mathrm{N}$, nucleus. Ordinary light microscopy. $\times 2100$.

FIG. 10.-Electron micrograph of longitudinal thin section of swarmer after Ryter-Kellenberger fixation. N, nucleoplasm; $\mathrm{C}$, capsular material; $\mathrm{CW}$, cell wall; $\mathrm{PM}$, plasma membrane. $\times 17,000$. 
S Iructural changes in Clostridium tetani
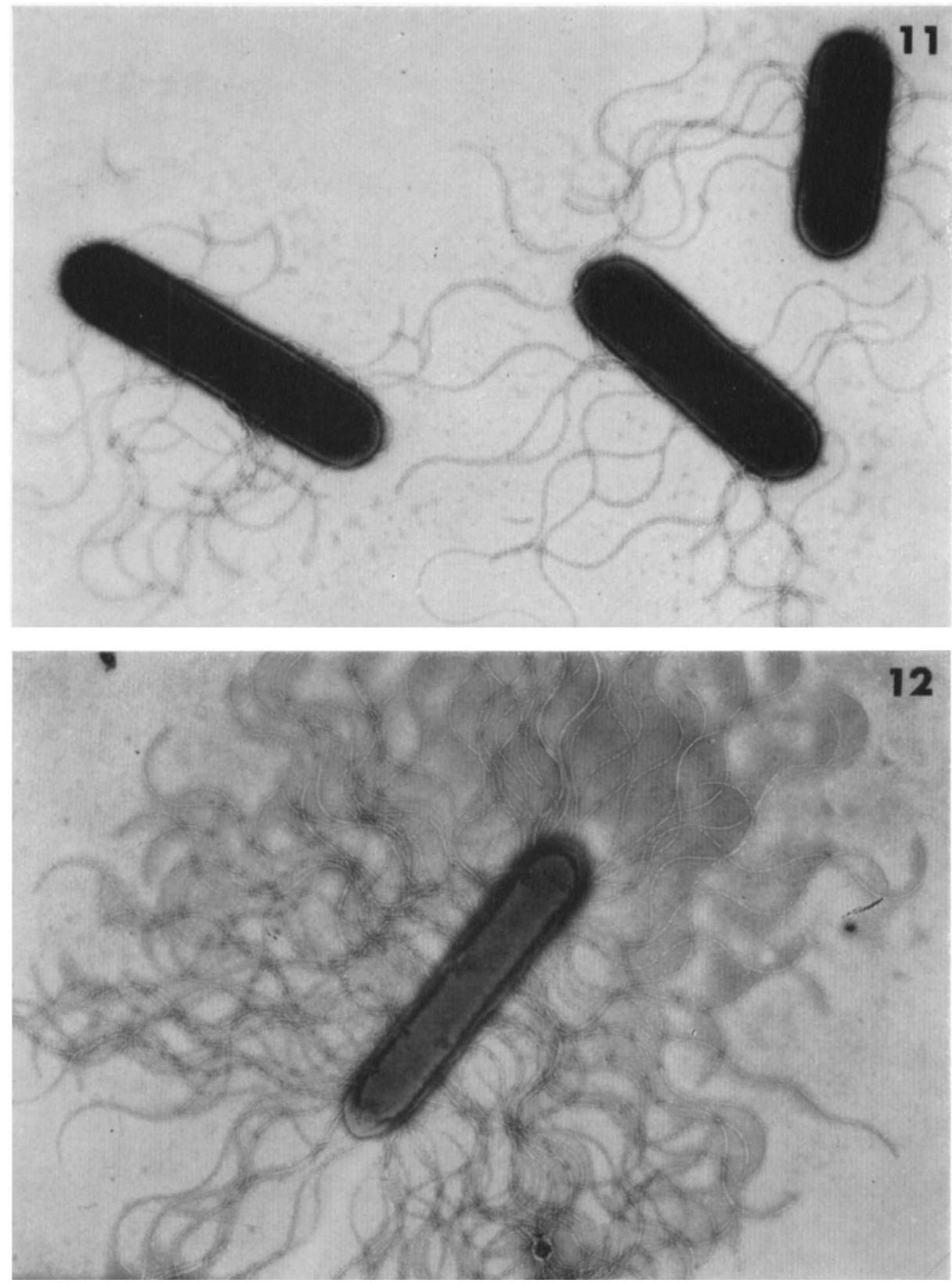

FIG. 11.-Electron micrograph of inoculum cells from overnight broth culture. Negatively stained with Na-PTA/BSA. $\times 9000$.

FIG. 12.-Negatively-stained swarmers from the edge of growth on an overnight plate. Na-PTA/ BSA. $\times 9000$. 
Structural changes in Clostridium tetani

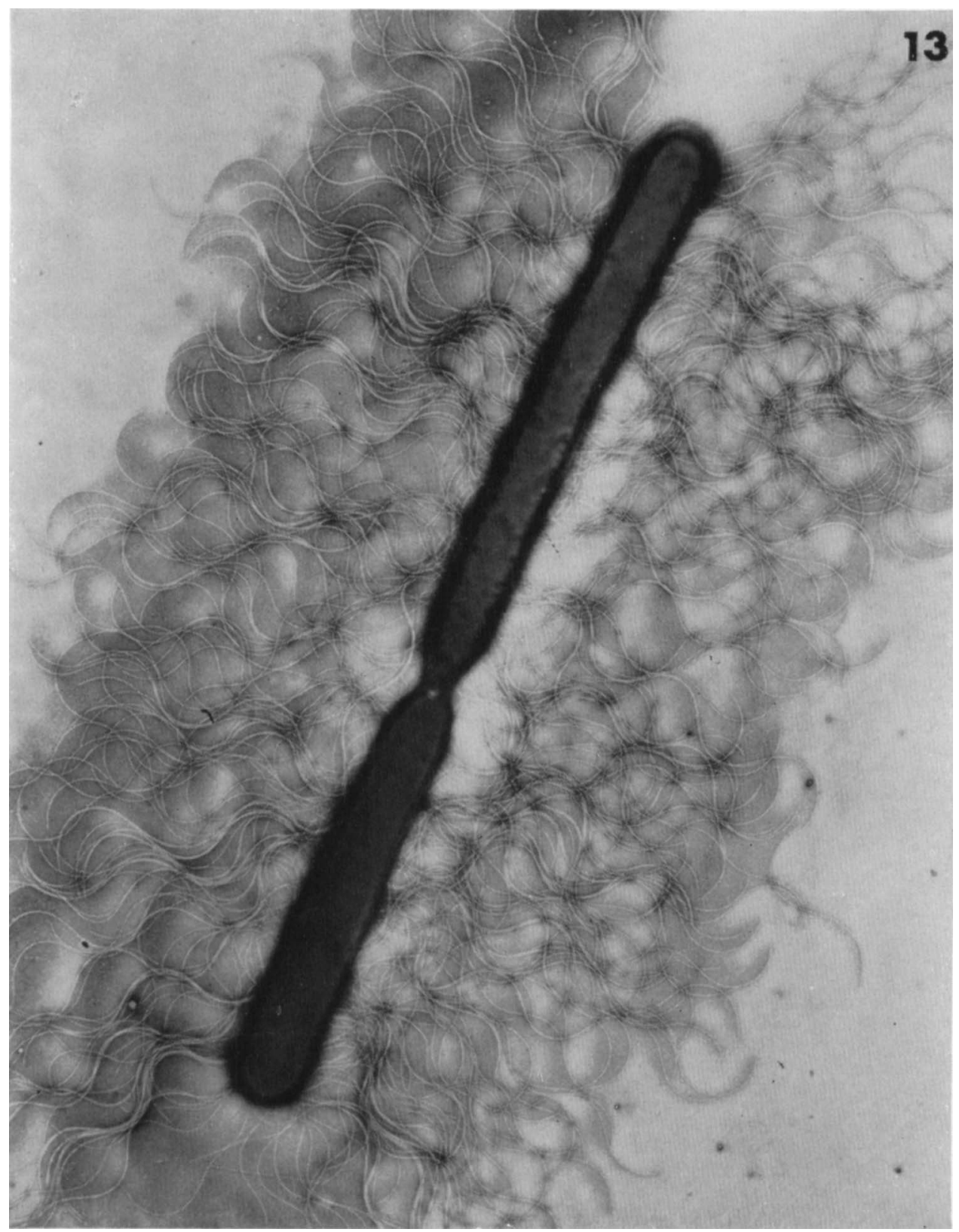

FIG. 13.-Negatively-stained swarmers from the edge of growth on an overnight plate. Na-PTA/ BSA. $\times 9500$. 

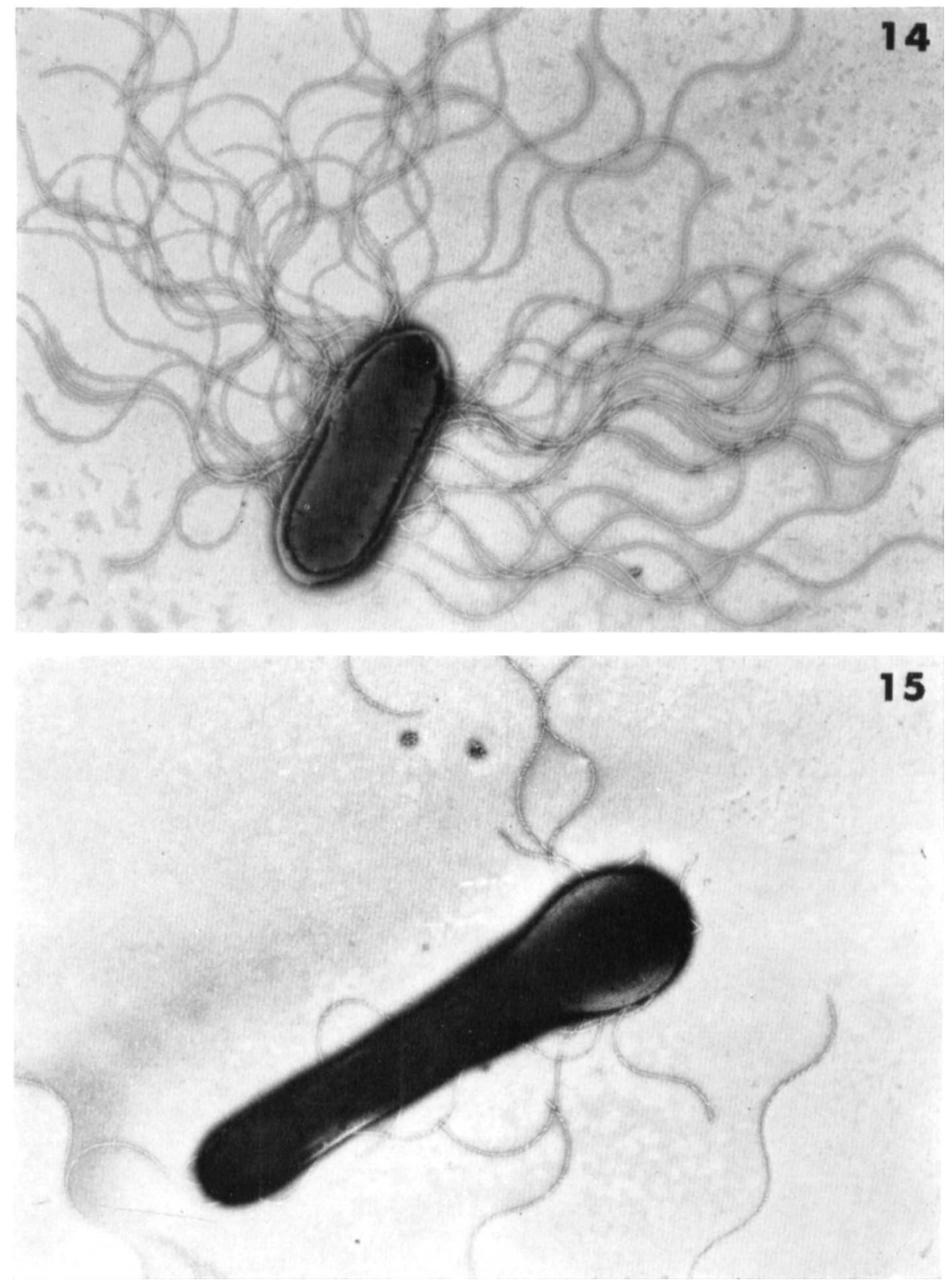

FIG. 14.- Short cell from a 48-hour plate culture. Negatively stained with Na-PTA/BSA. $\times 11,000$

FIG. 15.-Rod with terminal forespore taken from a 72-hour culture. Negatively stained with Na-PTA/BSA. $\times 11,000$. 
intervals up to 6 hours, and at 24, 48 and 72 hours. Because $C$. tetani is a strict anaerobe it was impossible to follow the sequence continuously in a single preparation as was previously done with $P$. mirabilis (Hoeniger, 1964).

When blocks were excised after incubation for 2 hours a mixture of viable (dark) and non-viable (irregularly mottled grey) cells was observed (fig. 1). This mottling is distinct from the regularly alternating light and dark areas in viable cells seen later (figs. 3 and 4). Nor should it be confused with the optical effect observed in phase-contrast preparations where closely packed groups of bacteria appear darker at the periphery than in the centre. An hour later, the cells had elongated significantly from their original length of 3-5 $\mu \mathrm{m}$, as can be seen in fig. 2 of a scattered group of viable organisms. The bacteria continued to lengthen and also to multiply so that by 4 hours (fig. 3) small groups of swarmers had formed. These swarmers measured about 5-20 $\mu \mathrm{m}$ in length and showed regular bands of light material, known from the work of Mason and Powelson (1956) and others to represent the sites of nuclear material, separated by dark bands of cytoplasm. By 6 hours (fig. 4) larger groups of swarmers had formed, some individuals being about $30 \mu \mathrm{m}$ in length.

Swarmers continued to develop, and plates incubated overnight showed a delicate film having an extremely wavy edge. Within the same batch of plates, the film extended varying distances from the site of lateral inoculation; in some cases after incubation for 24 hours the swarmers had moved about half-way across the agar; in others, they had almost covered the plate. Fig. 5 shows a typical group of organisms from the edge of growth. When cells were removed from this region and dispersed in TPGY broth, their length as determined by phase-contrast was found to vary widely, i.e., $19 \pm 25 \cdot 8 \mu \mathrm{m}$ (mean $\pm S D$ ). These data are based on measurements of more than 200 swarmers. The swarmers continued to migrate across the agar plate until the surface was covered. Then, by 48 hours (fig. 6), many of them divided to form shorter cells that either died (light grey organisms in fig. 6) or subsequently sporulated. The latter process was evident in 72-hour cultures (fig. 7), some cells having formed dark forespores, others mature refractile spores. In between the sporulating bacteria in this figure lysing organisms can be seen. By comparing figs. 5 and 7, the difference between the highly variable length of the swarmers and the regular size of the sporing rods derived from them is evident. This suggests a change in the regulation of cell growth and division.

\section{Ordinary light and electron microscopy of fixed swarmers}

When stained for their chromatin, swarmers excised on blocks of agar at the edge of the delicate film produced after overnight growth on plates were found to contain a series of single or paired nuclei neatly distributed along their entire length (fig. 8) Measurements of about 50 swarmers in Giemsa-stained preparations showed that the average spacing of the nuclei was $1 \cdot 546 \pm 0.241 \mu \mathrm{m}$ (mean $\pm \mathrm{SD})$; in calculating these data it was not possible to differentiate between swarmers with single nuclei and those with paired nuclei since both arrangements often occurred in the same organism. That the nuclei are 
separated by solid bands of cytoplasm is shown in the Bouin-thionin preparation of fig. 9. In this figure, the cytoplasm (CY) stains darkly while the nuclei $(\mathrm{N})$ appear grey and have a soft contour similar to that observed in phase-contrast micrographs (figs. 3 and 4).

A search for septation by suitable methods of staining for light microscopy gave equivocal results. Therefore, swarmers were embedded for electron microscopy of thin sections. Observations carried out on longitudinal sections made clear that the nuclei are evenly dispersed within the cytoplasm and that there are no intervening cross-septa. The R-K-fixed swarmer in fig. 10 is c. $10 \mu \mathrm{m}$ in length and possesses five regions of fibrillar nucleoplasm (N) several of which are in the process of division. Finely dispersed capsular material (C) surrounds the organisms; the peripheral cell wall (CW) is relatively thin and there is a well-defined plasma membrane (PM).

TABLE

Change in flagellar complement with age of culture on solid medium

\begin{tabular}{|c|c|c|c|c|}
\hline \multirow{2}{*}{$\begin{array}{l}\text { Period } \\
\text { of culture } \\
\text { on solid } \\
\text { medium } \\
\text { (hours) }\end{array}$} & \multicolumn{2}{|c|}{$\begin{array}{l}\text { No. flagella/unit } \\
\text { vol. bacterium }(\mu \mathrm{m})^{3}\end{array}$} & \multicolumn{2}{|c|}{$\begin{array}{l}\text { Total flagellar length }(\mu \mathrm{m}) \\
\text { /unit vol. bacterium }\left(\mu \mathrm{m}^{3}\right)\end{array}$} \\
\hline & Mean & SD & Mean & SD \\
\hline $\begin{array}{l}0^{*} \\
24 \\
48 \\
72\end{array}$ & $\begin{array}{r}8 \cdot 100 \\
37.784 \\
18.992 \\
1.931\end{array}$ & $\begin{array}{l}2.897 \\
8.477 \\
4.353 \\
\ldots\end{array}$ & $\begin{array}{r}24 \cdot 092 \\
241 \cdot 522 \\
117 \cdot 392 \\
7 \cdot 127\end{array}$ & $\begin{array}{r}6 \cdot 570 \\
53 \cdot 517 \\
28 \cdot 560 \\
\ldots\end{array}$ \\
\hline
\end{tabular}

* $0=$ Inoculum examined.

\section{Electronmicroscopy of negatively-stained bacteria}

The sequence of change in flagellar complement accompanying the differentiation of swarmers, their subsequent breakdown into short cells, and spore formation were observed by negatively staining inoculum cells from an overnight broth culture and cells removed from agar plates after incubation for 24, 48 and 72 hours. The inoculum cells in fig. 11 are $c .3-5 \mu \mathrm{m}$ long and bear an average number of 18 flagella of variable length $(3.622 \pm 1.696 \mu \mathrm{m})$. Cells taken from the film of swarming on a 24-hour plate may be relatively short (as in fig. 12) or long; many of the long swarmers are already dividing, as in fig. 13. A notable feature of both figs. 12 and 13 is the significant increase in the number of flagella per unit length. The long swarmer $(5 \mu \mathrm{m})$ in fig. 12 bears $c .150$ flagella, while the longer dividing organism in fig. 13 is surrounded by a mass of $c .400$ flagella. As noted by phase-contrast microscopy (fig. 6), after the swarmers have spread over the agar they break down into short cells. Such a short cell from a 48-hour plate is shown in fig. 14: it is $3 \mu \mathrm{m}$ in length and bears $c .60$ flagella $6 \cdot 142 \pm 1 \cdot 154 \mu \mathrm{m}$ long. With the onset of sporulation (fig. 15), flagella are no longer synthesised: the rod with terminal forespore taken from a 72hour plate is surrounded by eight sparse flagella of variable length. The best 
measure of the increase and decrease in flagellar synthesis in a plate culture of $C$. tetani is given by examination of electron micrographs and calculating the number of flagella per unit volume of bacterium and the total flagellar length per unit volume. The data are presented in the table: measurements of inoculum cells, 24-hour cells and 48-hour cells were determined from 5-10 micrographs; data for 72-hour cells are based on measurements taken from a single micrograph (fig. 15).

\section{Discussion}

Although several earlier investigations had revealed the tendency of $C$. tetani to grow as a spreading film on a solid medium, it was Fildes (1925) who first examined the phenomenon in detail and employed it to isolate 75 new strains from about 500 specimens. This spreading growth of swarming is exhibited by most strains of $C$. tetani. During the present study we found that nine out of ten strains swarmed on sheep blood agar or TPGY agar.

Recently, Willis and Williams (1970) and Williams (1971) have inhibited the swarming of $C$. tetani by incorporating into the medium commercial tetanus antitoxic serum. The inhibition they believe to be due to the presence in the antiserum of agglutinating $\mathrm{O}$ antibody to the vegetative cell. Further, these authors have employed such plates for making surface viable counts of $C$. tetani (Williams and Willis, 1970).

The swarming of $C$. tetani can be compared at both the macroscopic and microscopic level with that of $P$. mirabilis which has been studied in detail (Hoeniger, 1964, 1965, 1966). It is well known that the swarming of C. tetani is a continuous process during which a delicate but irregularly-edged film of long organisms ('swarmers') moves gradually across the agar surface (fig. 7). On the other hand, the swarming of Proteus is a cyclic phenomenon in which there is a regular alteration between a period of swarming and one of consolidation when short cells multiply (see Hoeniger, 1964, for appropriate references). This results in the characteristic sequence of rings seen on a centrally inoculated plate (see Hoeniger, 1964, fig. 1).

At the microscopic level, both $P$. mirabilis and $C$. tetani develop from short cells to swarmers by an inhibition of cell division. These swarmers frequently occur in rafts or groups when viewed with phase-contrast (figs. 3 and 4). After overnight incubation, in the case of $C$. tetani, the rafts of swarmers remain somewhat isolated along the periphery of growth and the individual cells may also appear separate (fig. 5); on the other hand, with $P$. mirabilis the undulating edge of swarming consists of confluent swirls of cells (Hoeniger, 1964).

In the present study, cells located towards the centre of the groups in figs. 3 and 4 show light areas of nucleoplasm and dark bands of cytoplasm, whereas peripheral swarmers appear uniformly dark. This is a general observation with groups of bacteria viewed by phase-contrast and it may be that there is a higher refractive index at the centre than at the periphery. The appearance of the inner cells resembles that of bacteria mounted in a medium of high refractive index such as one containing 15-35\% gelatin (Mason and Powelson, 1956) so as to reveal their internal structure. 
In the case of stained preparations of both $C$. tetani (figs. 8 and 9) and $P$. mirabilis (figs. 10 and 12 in the paper of Hoeniger, 1966) the nuclei are seen to be evenly distributed along the length of the swarmer and separated from one another by bands of cytoplasm. However, thin sections of C. tetani swarmers (fig. 10) failed to demonstrate intervening cross-septa, a feature also absent from P. mirabilis (figs. 9-11 in van Iterson, Hoeniger and van Zanten, 1966). Failing demonstration of such cross-septa one may have to look for some mechanism operating at the level of the plasma membrane to explain the neat separation of the nuclear structures within the cytoplasm.

It is apparent from fig. 8 that during the differentiation of $C$. tetani swarmers, DNA replication continues while cell division is inhibited. This merits consideration in relation to the model of the cell cycle in Escherichia coli recently put forward by Donachie and his colleagues (Donachie, 1973; Donachie, Jones and Teather, 1973). According to these workers, two parallel and separate sequences of events are initiated within the cell at each doubling: first, DNA replication which is followed by the synthesis of a specific "termination protein"; and second, protein synthesis which is followed by the assembly of some septum precursor(s). Interaction between "termination protein" and septum precursor(s) then leads to cell division. In swarmers of C. tetani, as well as in those of Proteus (Hoeniger, 1966), it is possible that neither "termination protein" nor septum precursor(s) are synthesised; thus long cells are formed containing numerous and regularly distributed sites of DNA. With regard to Proteus swarmers, it had already been shown (Hoeniger, 1966) that they are quite different from the long forms ("snakes", filaments) that arise in response to such treatments as exposure to low concentrations of penicillin or to low dosages of ultraviolet and of gamma irradiation. In the latter forms, the nuclear material assumes either a reticulate or contracted rope-like appearance which points to an inhibitory effect on the stage of DNA replication in the cell cycle.

An outstanding feature of the differentiation of swarmers of both $C$. tetani and $\boldsymbol{P}$. mirabilis is the synthesis of large numbers of flagella. Following the peak of synthesis in both organisms there is a decrease as the swarmers break down into short cells; in the case of $C$. tetani many of the latter then sporulate.

The long filamentous appearance of swarmers of $C$. tetani has been demonstrated in smears stained with methylene blue (fig. 10 of Fildes, 1925), in films stained for flagella (fig. 4 insert of Henrichsen, 1972), in preparations stained with fluorescent labelled antibody (fig. 6 of Batty and Walker, 1963; fig. 3 of Batty and Walker, 1964), and by low power phase-contrast microscopy of growth on the surface of an agar plate (fig. 4 of Henrichsen, 1972). One of the most interesting previous investigations is that of Neumann (1930) who followed continuously with the light microscope the sequence commencing with the germination of a single spore of $C$. tetani in a thin layer of agar in which a colony of Serratia marcescens was grown near the field of view, i.e., by adapting to the microscopic level the Fortner anaerobic technique (Fortner, 1929). The original germling was observed to divide several times forming short rods that then developed into a mass of long filaments or "Schwärmern" (figs. 18-20 of Neumann, 1930). No satisfactory explanation has yet been given for swarming 
although various suggestions for Proteus swarming have been made including the accumulation of a toxic "swarming factor" in the medium (Hughes, 1957) and a nutritional deficiency (see Hoeniger, 1964; Brogan, Nettleton and Reid, 1971; Grabow, 1972). Recently, Grabow (1972) showed that P. mirabilis and $P$. vulgaris excrete growth-inhibiting metabolites that are dialysable, volatile and inactivated by ether and chloroform; he thus supports the former view. On the other hand, Brogan et al. (1971) observed that the addition of a glycopeptide fraction of yeast extract to a semi-synthetic medium promotes swarming of $P$. mirabilis; this promotion was enhanced by the addition of vitamins of the B group. Perhaps because of the difficulties inherent in the strictly anaerobic nature of $C$. tetani, no comparable experiments into the factor(s) involved in its swarming have been carried out. If the isolation procedure exploited by Fildes (1925) is of practical value, a knowledge of these factors would be of more than academic interest.

\section{SUMMARY}

The life cycle of a swarming culture of Clostridium tetani has been examined by light and electron microscopy. Onset of swarming is accompanied by cell elongation and nuclear multiplication without cellular division. As swarming progresses, the elongating bacteria produce a greatly increased complement of flagella; the nuclei are seen to be neatly and evenly distributed throughout the cytoplasm and not separated by cross-septa. These findings are discussed in the light of recent studies on the swarming of Proteus species.

This investigation was supported by grant MA-3885 (J.F.M.H.) and a post-doctorate Fellowship (H.-D.T.), both from the Medical Research Council, Ottawa, Canada. We are indebted to Miss Norma M. Harnett, Mrs Angela Maguire, Mr A. MacGregor and Miss Ann Noonan for able assistance from time to time.

\section{REFERENCES}

BATTy, I. AND WaLKer, P. D. 1963. Fluorescent labelled clostridial antisera as specific stains. Bull. Off. int. Epizoot., 59, 1499.

BATTY, I. AND WALKeR, P. D. 1964. The identification of Clostridium novyi (Clostridium oedematiens) and Clostridium tetani by the use of fluorescent labelled antibodies. $J$. Path. Bact., 88, 327.

Brogan, T. D., Nettleton, J. ANd Reid, C. 1971. The swarming of Proteus on semisynthetic media. J. med. Microbiol., 4, 1.

DoNACHIE, W. D. 1973. Regulation of cell division in bacteria. Br. med. Bull., 29, 203.

Donachie, W. D., Jones, N. C. AND Teather, R. 1973. The bacterial cell cycle. Symp. Soc. gen. Microbiol., 23, 9.

Eklund, M. V., Poysky, F. T. ANd Boatman, E. S. 1969. Bacteriophages of Clostridium botulinum types $\mathrm{A}, \mathrm{B}, \mathrm{E}$ and $\mathrm{F}$ and nontoxigenic strains resembling type $\mathrm{E}$. J. Virol., 3, 270.

FILDES, P. 1925. Tetanus. I. Isolation, morphology and cultural reactions of $B$. tetani. Br. J. exp. Path., 6, 62.

FORTNER, J. 1929. Zur Technik der anäeroben Züchtung. II. Zur Differenzierung der Anäerobier. Zentbl. Bakt. ParasitKde, I, Abt. Orig., 110, 233.

Grabow, W. O. K. 1972. Growth-inhibiting metabolites of Proteus mirabilis. J. med. Microbiol., 5, 191.

HeNRICHSEN, J. 1972. Bacterial surface translocation: a survey and a classification. Bact. Rev., 36, 478. 
HoENiger, J. F. M. 1964. Cellular changes accompanying the swarming of Proteus mirabilis. I. Observations of living cultures. Can. J. Microbiol., 10, 1.

HozNiger, J. F. M. 1965. Development of flagella by Proteus mirabilis. J. gen. Microbiol., 40, 29.

HOENIGER, J. F. M. 1966. Cellular changes accompanying the swarming of Proteus mirabilis. II. Observations of stained organisms. Can. J. Microbiol., 12, 113.

Hughes, W. H. 1957. A reconsideration of the swarming of Proteus vulgaris. J. gen. Microbiol., 17, 49.

Iterson, W. vaN, HoEniger, J. F. M. AND ZANTEN, E. N. vaN. 1966. Basal bodies of bacterial flagella in Proteus mirabilis. I. Electron microscopy of sectioned material. J. Cell Biol., 31, 585.

Mason, D. J. AND Powelson, D. M. 1956. Nuclear division as observed in live bacteria by a new technique. J. Bact., 71, 474.

NeumanN, H. 1930. Die Isolierung und die Entwicklung von Anäerobiersporen. Zentbl. Bakt. ParasitKde, I, Abt. Orig., 115, 100.

Robinow, C. F. 1942. A study of the nuclear apparatus of bacteria. Proc. R. Soc. B, 130, 299.

RoBINow, C. F. 1944. Cytological observations on Bact. coli, Proteus vulgaris and various aerobic spore-forming bacteria with special reference to the nuclear structures. J. Hyg., Camb., 43, 413.

RYTER, A. AND KELleNBerger, E. 1958. Étude au microscope électronique de plasmas contenant de l'acide désoxyribonucléique. Les nucléoides des bactéries en croissance active. Z. Naturf., 13b, 597.

Sasarman, A., Ganea, V. AND Dospina, M. 1957. Contribution à l'étude de la mobilité des colonies bactériennes. Note I. Archs. roum. Path. exp. Microbiol., 16, 395.

Takagi, A., Nakamura, K. AND Ueda, M. 1965. Electron microscope studies of the intracytoplasmic membrane system in Clostridium tetani and Clostridium botulinum. Jap.J. Microbiol., 9, 131.

TURNER, A. W. AND Eales, C. E. 1941. Motile daughter colonies in the $\mathrm{Cl}$. oedematiens group and some other clostridia ( $\mathrm{Cl}$. botulinum $\mathrm{C}, \mathrm{Cl}$. tetani, $\mathrm{Cl}$. septicum). Aust. J. exp. Biol. med. Sci., 19, 167.

Williams, K. 1971. Some observations on Clostridium tetani. J. med. Lab. Technol., 28, 399.

Williams, K. AND Willis, A. T. 1970. A method of performing surface viable counts with Clostridium tetani. J. med. Microbiol., 3, 639.

WILlis, A. T. 1964. Anaerobic bacteriology in clinical medicine, 2nd ed., London.

Willis, A. T. AND Williams, K. 1970. Some cultural reactions of Clostridium tetani. J. med. Microbiol., 3, 291.

Wrlus, A. T. AND Wrlliams, K. 1972. Prevention of swarming of Clostridium septicum. J. med. Microbiol., 5, 493. 